\title{
Arteriovenous Fistula of the Filum Terminale Misdiagnosed and Previously Operated as Lower Lumbar Degenerative Disease
}

\author{
Pankaj Sharma, Alok Ranjan, Rahul Lath \\ Department of Neurosurgery, Apollo Health City, Jubilee Hills, Hyderabad, India
}

Filum terminale arteriovenous fistula (FTAVF) presenting as a cause of failed back surgery syndrome is a rare entity. We report a 48-year-old male patient who presented with clinical features of a conus medullaris/cauda equina lesion. He had upper and lower motor neuron signs in both the lower limbs with autonomic dysfunction. The patient was misdiagnosed and was operated twice earlier for lumbar canal stenosis and disc prolapse. After reviewing his clinical and radiological findings a diagnosis of FTAVF was made. He underwent surgery and there was a significant improvement in his neurological functions. We discuss the case and review the literature on FTAVF's.

Keywords: Failed back surgery syndrome; Filum terminale arteriovenous fistula

\section{Introduction}

Spinal intradural arteriovenous fistulas (AVF) are rare spinal vascular malformations which are underdiagnosed and lead to progressive neurological dysfunction. Kim and Spetzler [1] have classified these AVF's within the intradural ventral AVF category and further subclassified them into type $\mathrm{A}, \mathrm{B}$, and $\mathrm{C}$, depending on their size and arterial feeders. Filum terminale is a rare location for intradural arteriovenous fistulas to occur. To our knowledge 17 cases of filum terminale AVF (FTAVF) have been reported so far in the English literature (Table 1) [2-11]. They present with progressive neurological signs and symptoms in the lower limbs with or without autonomic dysfunction. Diagnosis is frequently overlooked and delayed due to its rarity. A few cases have been misdiagnosed and operated for lumbar stenosis and disc prolapse resulting in a failed back surgery syndrome [6,8]. Endovascular embolization, surgical disconnection of the fistula or a combination of both techniques have been described in their treatment with good outcomes $[5,10]$. We are reporting a case of FTAVF, who was misdiagnosed and previously operated twice for lower lumbar degenerative disease and presented with progressive symptoms.

\section{Case Report}

A 48-year-old male presented with history of intermittent low back pain radiating to both lower limbs for the past 11 years. Back pain was insidious in onset and was not getting relieved with analgesics and physiotherapy modalities. He underwent partial L4-L5 laminectomy in another centre in 2000 for lumbar canal stenosis. His symptoms partially subsided post surgery and then grad-

Received Dec 13, 2012; Revised May 2, 2013; Accepted May 2, 2013

Corresponding author: Pankaj Sharma

Department of Neurosurgery, Apollo Health City, Jubilee Hills, Hyderabad, Andhra Pradesh, India-500096

Tel: +91-40-23607777 (extn.3011), Fax: +91-40-23608050, E-mail: drpankaj_79@rediff.com 
Table 1. Summary of the filum terminale AV fistulas reported in literature

\begin{tabular}{|c|c|c|c|c|c|c|}
\hline $\begin{array}{c}\text { S. } \\
\text { no. }\end{array}$ & Authors (yr) & $\begin{array}{l}\text { Age }(y r) / \\
\text { Sex }\end{array}$ & Clinical presentation & $\begin{array}{l}\text { Feeders and } \\
\text { level of fistula }\end{array}$ & Treatment & Outcome \\
\hline 1 & $\begin{array}{l}\text { Mourier et al. } \\
\text { (1993) [2] }\end{array}$ & $\begin{array}{l}\text { Not specified } \\
\text { in } 2 \text { cases }\end{array}$ & Asymmetric features & ASA & Surgery & $\begin{array}{l}\text { One patient improved, } \\
\text { one remained same }\end{array}$ \\
\hline \multirow[t]{2}{*}{2} & $\begin{array}{l}\text { Tender et al. } \\
\text { (2005) [3] }\end{array}$ & 70/M & $\begin{array}{l}\text { Lower limbs numbness and } \\
\text { weakness, bladder incontinence, } \\
\text { FBSS }\end{array}$ & ASA (L4) & Surgery & Improved neurologically \\
\hline & & $58 / \mathrm{M}$ & $\begin{array}{l}\text { Lower limbs numbness and } \\
\text { weakness, bladder incontinence, } \\
\text { FBSS }\end{array}$ & ASA (L2) & Surgery & Improved neurologically \\
\hline 3 & Mitha et al. (2006) [4] & $42 / M$ & Backache and urinary incontinence & ASA (S1) & Surgery & Improved neurologically \\
\hline 4 & Jinet al. (2010) [5] & $61 / \mathrm{M}$ & $\begin{array}{l}\text { Neurogenic claudication, } \\
\text { voiding difficulty }\end{array}$ & $\begin{array}{l}\text { Left lateral } \\
\text { sacralartery (L5/S1) }\end{array}$ & $\begin{array}{l}\text { Embolization } \\
\text { +surgery }\end{array}$ & Improved neurologically \\
\hline 5 & Kumar et al. (2011) [6] & $44 / \mathrm{M}$ & $\begin{array}{l}\text { Lower limbs numbness and } \\
\text { weakness with FBSS }\end{array}$ & $\begin{array}{l}\text { Artery of } \\
\text { adamkiewicz (L4/L5) }\end{array}$ & Surgery & Improved neurologically \\
\hline 6 & Witiw et al. (2011) [7] & $62 / M$ & $\begin{array}{l}\text { Lower limbs numbness and } \\
\text { weakness, bladder incontinence, } \\
\text { impotence }\end{array}$ & ASA (S2/S3) & Surgery & $\begin{array}{l}\text { Impotence persisted, } \\
\text { other symptoms } \\
\text { improved. }\end{array}$ \\
\hline \multirow[t]{2}{*}{7} & $\begin{array}{l}\text { Trinh and Duckworth } \\
\text { (2011) [8] }\end{array}$ & $57 / M$ & $\begin{array}{l}\text { Lower limbs numbness and } \\
\text { weakness with FBSS }\end{array}$ & ASA (L4/S1) & Surgery & Improved neurologically \\
\hline & & $63 / M$ & $\begin{array}{l}\text { Lower limbs numbness and } \\
\text { weakness with FBSS }\end{array}$ & $\begin{array}{l}\text { Precise feeder not } \\
\text { specified(L4/L5) }\end{array}$ & Surgery & Improved neurologically \\
\hline 8 & Macht et al. (2011) [9] & $57 / \mathrm{M}$ & Progressive paraparesis & ASA (S3/S4) & Embolization & Improved \\
\hline \multirow[t]{4}{*}{9} & Lim et al. (2011) [10] & $60 / \mathrm{M}$ & Lower limbs UMN +LMN features & ASA (L3) & Surgery & Improved neurologically \\
\hline & & $48 / \mathrm{M}$ & Lower limbs UMN + LMN features & ASA (L4/L5) & Surgery & Improved neurologically \\
\hline & & $53 / F$ & Lower limbs UMN + LMN features & ASA (L4/L5) & Embolization & Improved neurologically \\
\hline & & $63 / F$ & $\begin{array}{l}\text { Lower limbs UMN + LMN features } \\
\text { + spina bifida }\end{array}$ & $\begin{array}{l}\text { ASA from right } L 4 \\
\text { and left lateral sacral } \\
\text { artery }(\mathrm{L} 3 / \mathrm{L} 4)\end{array}$ & Embolization & Improved neurologically \\
\hline \multirow[t]{2}{*}{10} & $\begin{array}{l}\text { Takami et al. } \\
\text { (2012) [11] }\end{array}$ & $66 / F$ & Sciatica with bladder dysfunction & ASA (L2) & Surgery & $\begin{array}{l}\text { Sciatica subsided, } \\
\text { transient worsening of } \\
\text { urinary symptom }\end{array}$ \\
\hline & & $63 / \mathrm{M}$ & $\begin{array}{l}\text { Sciatica with bladder dysfunction } \\
\text { and FBSS }\end{array}$ & ASA (L4/L5) & Surgery & Sciatica subsided \\
\hline 11 & Present case & $48 / \mathrm{M}$ & $\begin{array}{l}\text { Progressive Lower limbs UMN } \\
+ \text { LMN features with FBSS }\end{array}$ & ASA (L4/L5) & Surgery & Improved neurologically \\
\hline
\end{tabular}

AV, arterio-venous; S. no., serial number; M, male; F, female; ASA, anterior spinal artery; FBSS, failed back surgery syndrome; UMN, upper motor neuron; LMN, lower motor neuron.

ually progressed over the next few years. He underwent a re-exploration and completion L4-L5 laminectomy and discectomy in 2008. Post surgery, there was no improvement in his symptoms. He developed paresthesias in both lower limbs for the past 3 years, progressive weakness of both lower limbs with difficulty in walking over the past 2 years and increased frequency of micturition with incomplete voiding and constipation over the past year.

On examination, he was hemodynamically stable with normal higher mental functions. The upper limbs examination was normal. There was a spastic paraparesis of both lower limbs with wasting of the medial thigh and anterior thigh muscle groups. There were impaired sensations below the D10 level with absent joint position sense in the lower limbs. Knee and ankle reflexes were absent and plantars were extensor bilaterally. He had a spasticataxic gait. He had a healthy surgical scar over the lower lumbar midline region. A clinical diagnosis of dorsal my- 
elopathy with mixed upper and lower motor neuron signs in the lower limbs was made and magnetic resonance imaging (MRI) of the dorsolumbar spine was ordered.

MRI of the dorso-lumbar spine showed dilated tortuous vessels with flow voids over the lower dorso-lumbar region with intramedullary, ill defined hyperintense signal abnormality in T2-weighted (T2-W) images from the D9 level downwards up to the conus medullaris (Fig. 1). A subtle loss of cord calibre was also seen. Signal changes were enhancing on the contrast study. Postoperative changes were noted at the L4-L5 levels. A filum terminale lipoma was also noted at the L3-L4 level. As radiological features were suggestive of a spinal vascular malformation, a spinal angiogram was done, which showed a filum terminale AVF at the lower lumbosacral region, filling from a vessel starting at the D9 level on the ventral surface of the cord (Fig. 2). Review of old images done in 2000 and 2008 also showed dilated tortuous vessels in T2-W MRI images, in addition to stenosis and disc bulge at the L4-L5 level (Fig. 3). Our patient had Spetzler type A intradural ventral arteriovenous fistula, as the fistula was small and was fed by the single distal anterior spinal artery (ASA-filum terminale artery) and was draining in a single vein (Table 2).

In view of his clinical and radiological features, surgery was planned, and after consent, a re-exploration of lum- bar spine was done. There was a pseudomeningocoele at the L5 level with thinned out dura. With microscope assisted visualization, a midline durotomy was done. On opening the dura, tortuous vessels were noticed around the roots, and two dominant vessels were noticed along the filum terminale (Fig. 4). These vessels were followed along the filum till the lower end where a fistulous con-

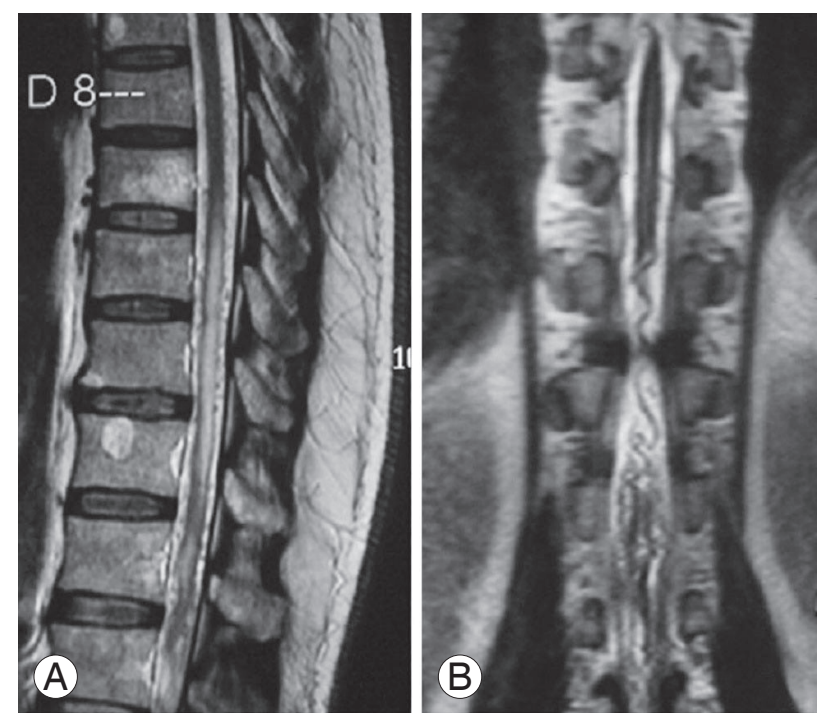

Fig. 1. Sagittal (A) and coronal (B) T2-weighted magnetic resonance imaging showing hyperintense intramedullary changes in the lower thoracic cord extending to the conus medullaris with superficial dilated tortuous vessels.
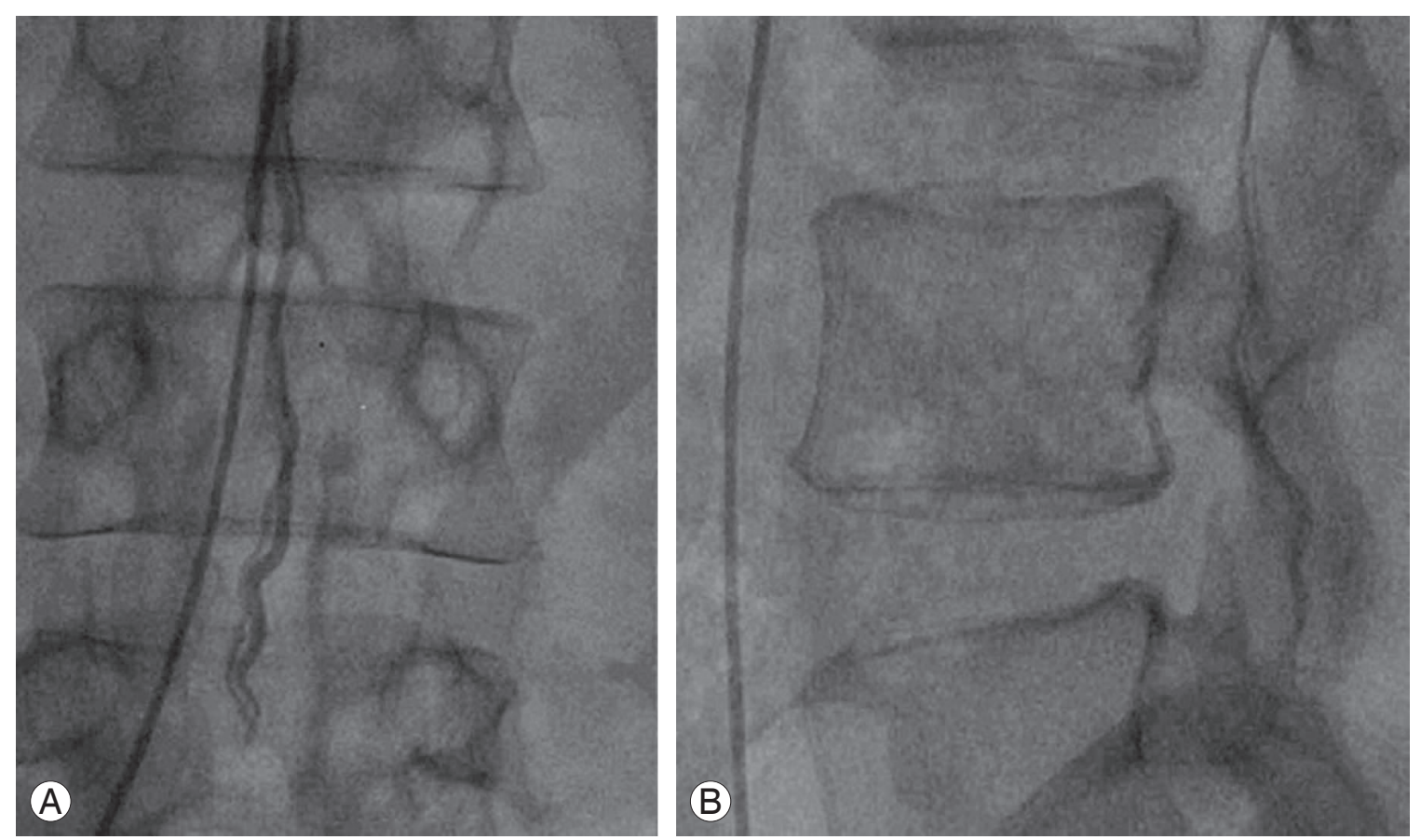

Fig. 2. Spinal angiogram anteroposterior (A) and lateral (B) view showing two large calibre vessels with fistulous connection. 
Table 2. Merlands classification of perimedullary arteriovenous fistulas [2]

\begin{tabular}{|c|c|c|c|c|c|}
\hline Type & Location & Feeder arterial channel & Calibre & $\begin{array}{c}\text { Draining venous } \\
\text { channel }\end{array}$ & Flow \\
\hline । & $\begin{array}{l}\text { Anterior aspect of } \\
\text { conus medullaris or } \\
\text { filum terminale }\end{array}$ & $\begin{array}{l}\text { Single, terminal portion } \\
\text { of thin ASA }\end{array}$ & $\begin{array}{l}\text { Mildly dilated and } \\
\text { tortuous }\end{array}$ & $\begin{array}{l}\text { Ascending } \\
\text { perimedullary vein }\end{array}$ & Slow \\
\hline$\|$ & $\begin{array}{l}\text { Conus medullaris, } \\
\text { more frequently } \\
\text { posterolateral }\end{array}$ & $\begin{array}{l}\text { Multiple, main feeder } \\
\text { ipsilateral PSA, } \\
\text { contralateral PSA, ASA }\end{array}$ & $\begin{array}{l}\text { Dilated tortuous venous } \\
\text { channels }\end{array}$ & $\begin{array}{l}\text { Ascending } \\
\text { perimedullary vein }\end{array}$ & $\begin{array}{l}\text { High flow arterial blood, } \\
\text { slow venous flow }\end{array}$ \\
\hline III & $\begin{array}{l}\text { Cervical or thoracic } \\
\text { levels }\end{array}$ & $\begin{array}{l}\text { Multiple, several } \\
\text { branches of ASA, PSA }\end{array}$ & Hugely dilated, giant AVF & Giant venous ectasia & $\begin{array}{l}\text { High flow arterial blood } \\
\text { and venous flow }\end{array}$ \\
\hline
\end{tabular}

ASA, anterior spinal artery; PSA, posterior spinal artery; AVF, arteriovenous fistula.

nection was noticed, and it was excised. There was a small lipoma at the end of the filum terminale, which was also excised. Tortuosity and calibre of the vessels around the roots decreased, following excision of the fistula. Primary duroplasty was done and was sealed with fibrin glue.

The lower limb spasticity reduced in the immediate postoperative period. Over the next few days of his hospital stay, he started having catheter sensation. He started

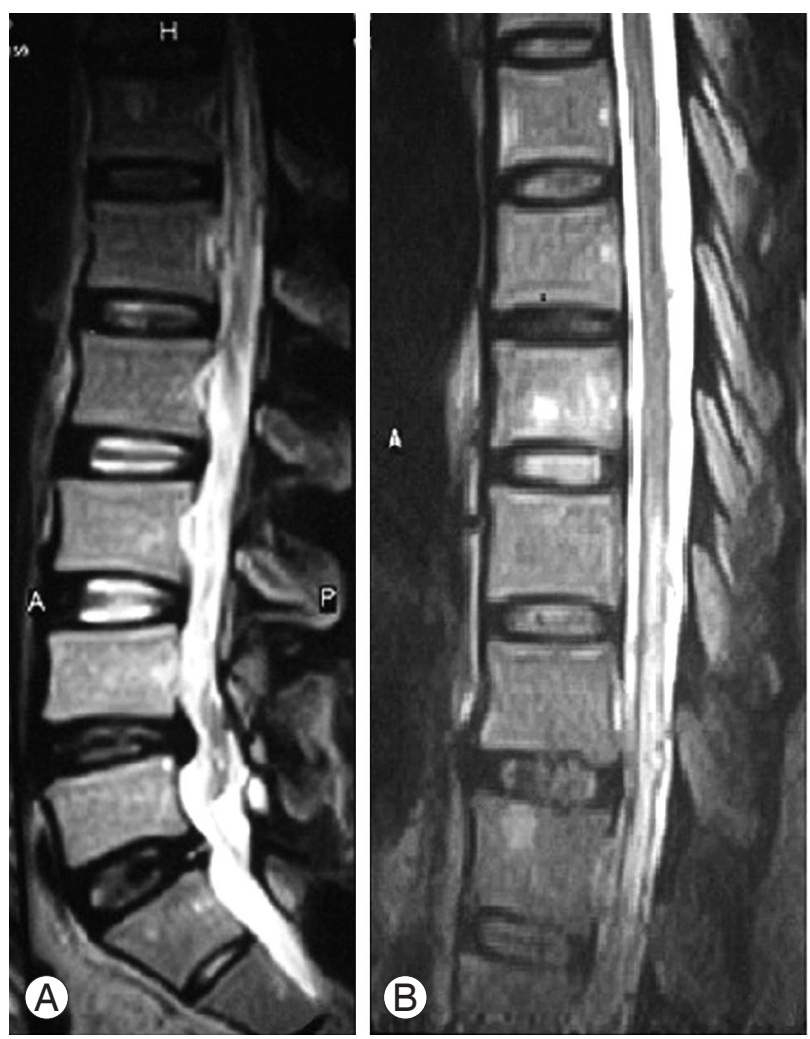

Fig. 3. (A) Sagittal magnetic resonance imaging images done in 2008 showing dilated vessels in the subarachnoid space with evidence of previous surgery and (B) intramedullary signal changes in the lower thoracic spinal cord. walking without support 6 weeks later. After 3 months, urinary catheter was removed as he was found to have good bladder control. At the last follow up 1 year later, he was independent for all activities of daily living and was back to his job.

\section{Discussion}

Filum terminale is an anatomical end structure of the spinal cord and is supplied by a filum terminale artery, which is a caudal extension of the anterior spinal artery [11]. FTAVF is a rare entity and literature review showed that only 17 cases have been reported so far (Table 1). Male to female ratio is 5:1 and the median age of presentation was 57.1 years, with youngest patient being 42 years and oldest patient being 70 years. All cases presented with progressive motor and sensory symptoms of both lower limbs with or without bladder incontinence. Seven

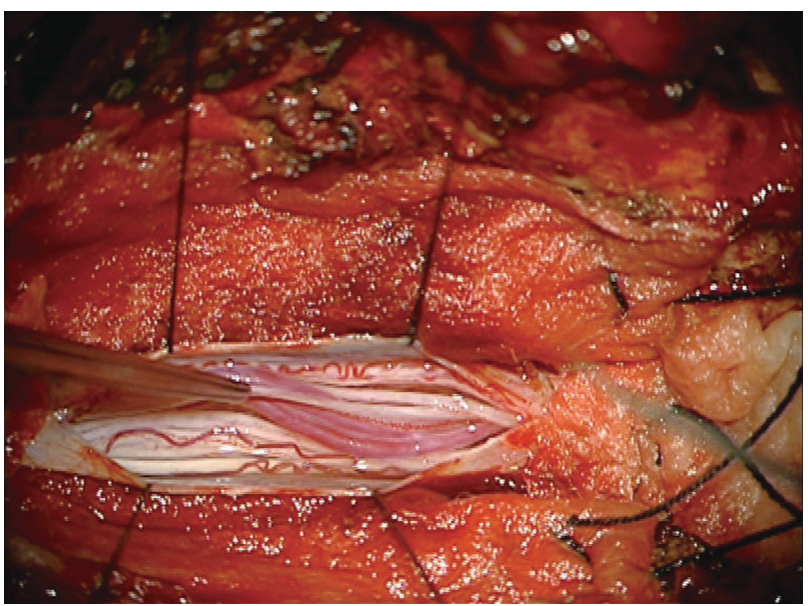

Fig. 4. Intraoperative image showing two large calibre vessels along the filum terminale with prominent tortuous vessels over the cauda equina. 
cases, including ours, were also of failed back surgery syndrome (Table 1). The first two cases were reported by Mourier et al. [2] in 1993 and they classified them as Merland's type I. Lim et al. [10] have reported the largest series of 4 cases. The location, arterial supply, treatment modalities and outcomes have been summarized in Table 1.

The filum terminale artery arises from the termination of the anterior spinal axis, as caudal continuation of the ventral spinal artery, mostly the anterior spinal artery [10]. Djindjian et al. [12] also described the filum terminale artery as a continuation of the artery of Adamkiewicz, which after giving branches and doing anastomoses with posterior spinal artery at the level of conus, continues as a longitudinal artery on the ventral surface of the filum terminale. The filum terminale vein is also a single vein lying on the dorsal surface of filum terminale and connects extradural venous plexus of sacrum to the ventral vein of the spinal cord $[10,12]$. Initially described as the intradural extramedullary spinal AV fistulas, filum terminale AVFs are congenital, as well as acquired in nature $[3,9,11]$. These fistulas are fed by the anterior spinal artery and drained usually in the single filum terminale vein, either cranially or caudally, although a case of complex venous drainage is reported recently $[7,10,11]$.

FTAVFs are thought to be congenital, though cases of the acquired type are also reported in literature. Cases manifesting in adulthood with initial negative spinal angiograms have been reported and supports acquired etiology. The absence or loss of medullary veins leading to venous hypertension may have a role in clinical presentation of theses fistulas [3]. Our case had radiological evidence of an AVF prior to his first surgery, suggesting a congenital origin $[8,11]$.

Aminoff et al. [13] explains that high venous pressure, due to direct arterial flow without intervening capillary network, causes retrograde transmission of the pressure, which hampers the perfusion of the cord. Limited venous drainage is probably a requisite to develop venous hypertension $[3,13]$. Type A fistulas, which are the slow type and have single feeder and single draining vein, do not cause significant cord compression, do not haemorrhage, and by definition, are not associated with venous ectasias. Venous hypertension theory can explain clinical features in type A fistulas $[1,3]$.

Merland classified perimedullary AVFs on the basis of anatomy, hemodynamic properties and angiographic features in three subtypes (Table 2) [2]. Spetzler has clas-
Table 3. Classification of arteriovenous lesions by Kim and Spetzler [1] Spinal arteriovenous lesions

\begin{tabular}{|c|c|c|}
\hline \multicolumn{3}{|c|}{ Arteriovenous fistula } \\
\hline \multicolumn{3}{|l|}{ Extradural } \\
\hline \multirow[t]{4}{*}{ Intradural } & Dorsal & \\
\hline & Ventral & Type A \\
\hline & & Type B \\
\hline & & Type C \\
\hline \multicolumn{3}{|c|}{ Arteriovenous malformation } \\
\hline \multicolumn{3}{|c|}{ Extradural-intradural } \\
\hline \multirow[t]{2}{*}{ Intramedullary } & Compact & \\
\hline & Diffuse & \\
\hline Conus & & \\
\hline
\end{tabular}

sified intradural AVFs in dorsal and ventral AVFs, and further subclassified ventral type AVFs into subclass type $\mathrm{A}, \mathrm{B}$, and $\mathrm{C}$, depending on their size and arterial feeders (Table 3) [1]. Merlands type I AVFs have similar features, like Spetzler type A fistula with both having single feeder from terminal ASA located at the filum terminale, slow fistula draining into a single venous channel.

Radiological diagnosis is by magnetic resonance (MR) imaging along with MR angiography and confirmed with digital subtraction angiogram. Dilated tortuous vessels on the cord surface more on the dorsal surface, along with irregular intramedullary changes with cord oedema on T2-W and with diffuse enhancement on contrast administration is suggestive of arteriovenous fistula [14]. Modified T2-W sequences like constructive interference in steady state, fast imaging employing steady state acquisition, or three-dimensional turbo spin echo visualized the engorged vessels better and help in differentiating them from flow voids [14]. Spinal angiography is characterized by early venous filling when the segmental artery harbouring the A-V fistula is injected, while a delayed venous return is noticed on injecting anterior spinal artery. Delayed venous return indicates venous congestion [13].

These arteriovenous fistulae present with progressive asymmetrical lower limb signs and symptoms localized to conus medullaris or cauda equina (Table 1). A diagnosis of spinal AVF should be considered in young age patients when faced with asymmetric radiculomedullary symptoms of the progressive course [15]. Early diagnosis is important as neurological recovery depends upon preoperative status [8]. The neurological dysfunction is 
graded according to the modified Aminoff-Logue scale [16]. Misdiagnosis is common as high index of suspicion is necessary for the diagnosis and patient can present with progressive worsening after lumbar spine surgery [16]. The time from the initial symptoms to the diagnosis of FTAVF varies from 3 weeks to 18 years $[3,9]$.

Small ventral intradural AVFs (type A and B) are managed surgically, wherein disconnection of the venous outflow is easily achieved after adequate surgical exposure. Recently, a few case reports emphasize on the use of intraoperative dye for localizing the AVF $[3,5]$. ASA branches have to be identified and preserved during excision of fistula to have a better outcome [1]. Filum terminale artery vascular integrity diminishes as it descends distally. Endovascular treatment in form of embolization may be associated with high risk of occlusion of ASA or its branches in FTAVFs [4].

Our case of FTAVF besides being a rare entity, also reinforces the need for proper clinical assessment and co-relating them with the radiological findings prior to making a surgical decision. The intradural A-V fistula was missed and the diagnosis was delayed for 11 years. Hyperintense signal changes in T2-W MRI in the spinal cord with dilated vessels in the subarachnoid space suggest a spinal vascular malformation, and a spinal angiography should be done to avoid a misdiagnosis.

\section{Conflict of Interest}

No potential conflict of interest relevant to this article was reported.

\section{References}

1. Kim LJ, Spetzler RF. Classification and surgical management of spinal arteriovenous lesions: arteriovenous fistulae and arteriovenous malformations. Neurosurgery 2006;59(5 Suppl 3):S195-201.

2. Mourier KL, Gobin YP, George B, Lot G, Merland JJ. Intradural perimedullary arteriovenous fistulae: results of surgical and endovascular treatment in a series of 35 cases. Neurosurgery 1993;32:885-91.

3. Tender GC, Vortmeyer AO, Oldfield EH. Spinal intradural arteriovenous fistulas acquired in late adulthood: absent spinal venous drainage in pathogenesis and pathophysiology. Report of two cases. J Neurosurg Spine 2005;3:488-94.
4. Mitha AP, Murphy EE, Ogilvy CS. Type A intradural spinal arteriovenous fistula. Case report. J Neurosurg Spine 2006;5:447-50.

5. Jin YJ, Kim KJ, Kwon OK, Chung SK. Perimedullary arteriovenous fistula of the filum terminale: case report. Neurosurgery 2010;66:E219-20.

6. Kumar A, Deopujari CE, Mhatre M. Misdiagnosis in a case of non-compressive myelopathy due to a lumbar spinal intradural fistula supplied by the Artery of Adamkiewicz. Surg Neurol Int 2011;2:12.

7. Witiw CD, Fallah A, Radovanovic I, Wallace MC. Sacral intradural arteriovenous fistula treated indirectly by transection of the filum terminale: technical case report. Neurosurgery 2011;69:E780-4.

8. Trinh VT, Duckworth EA. Surgical excision of filum terminale arteriovenous fistulae after lumbar fusion: Value of indocyanine green and theory on origins (a technical note and report of two cases). Surg Neurol Int 2011;2:63.

9. Macht S, Chapot R, Bieniek F, Hanggi D, Turowski B. Unique sacral location of an arteriovenous fistula of the filum terminale associated with diastematomyelia and lowered spinal cords. Neuroradiology 2012;54:517-9.

10. Lim SM, Choi IS, David CA. Spinal arteriovenous fistulas of the filum terminale. AJNR Am J Neuroradiol 2011;32:1846-50.

11. Takami T, Yamagata T, Mitsuhashi Y, Hayasaki K, Ohata K. Direct surgery for spinal arteriovenous fistulas of the filum terminale with intraoperative image guidance. Spine (Phila Pa 1976) 2012;37:E1524-8.

12. Djindjian M, Ribeiro A, Ortega E, Gaston A, Poirier J. The normal vascularization of the intradural filum terminale in man. Surg Radiol Anat 1988;10:201-9.

13. Aminoff MJ, Barnard RO, Logue V. The pathophysiology of spinal vascular malformations. J Neurol Sci 1974;23:255-63.

14. Krings T, Geibprasert S. Spinal dural arteriovenous fistulas. AJNR Am J Neuroradiol 2009;30:639-48.

15. Huffmann BC, Spetzger U, Reinges M, Bertalanffy H, Thron A, Gilsbach JM. Treatment strategies and results in spinal vascular malformations. Neurol Med Chir (Tokyo) 1998;38 Suppl:231-7.

16. Atkinson JL, Miller GM, Krauss WE, et al. Clinical and radiographic features of dural arteriovenous fistula, a treatable cause of myelopathy. Mayo Clin Proc 2001;76:1120-30. 